\section{Orthodeoxia and postural orthostatic tachycardia in patients with pulmonary arteriovenous malformations: a prospective 8-year series}

\section{ABSTRACT}

Postural changes in 258 patients with pulmonary arteriovenous malformations (PAVMs) reviewed between 2005 and 2013 were evaluated prospectively using validated pulse oximetry methods. Of the 257 completing the test, $75(29 \%)$ demonstrated orthodeoxia with an oxygen saturation fall of at least $2 \%$ on standing. None described platypnoea (dyspnoea on standing). The heart rate was consistently higher in the erect posture: $74(29 \%)$ had a postural orthostatic tachycardia of $\geq 20 \mathrm{~min}^{-1}$, and in $25(10 \%)$ this exceeded $30 \mathrm{~min}^{-1}$. Orthostatic tachycardia was more pronounced in PAVM patients than controls without orthodeoxia (age-adjusted coefficient $5.5(95 \%$ Cls 2.6 , 8.4) $\mathrm{min}^{-1}, \mathrm{p}<0.001$ ). For PAVM patients, the age-adjusted pulse rise was $0.79 \mathrm{~min}^{-1}$ greater for every $1 \%$ greater drop in oxygen saturation on standing $(p<0.001)$. In contrast to the postural orthostatic tachycardia syndrome, in this population, there was a trend for more pronounced orthostatic tachycardia to be associated with better exercise tolerance.

\section{To the editor}

Pulmonary arteriovenous malformations (PAVMs) result in hypoxaemia due to right-to-left shunting. ${ }^{1}$ Recent studies highlight that chronic hypoxaemia in ironreplete patients leads to secondary erythrocytosis which preserves arterial oxygen content $\left(\mathrm{CaO}_{2}\right){ }^{2}$ Both shunt fraction ${ }^{3}$ and hypoxaemia severity ${ }^{4}$ may increase acutely on standing, a phenomenon ascribed to basally situated PAVMs. ${ }^{3} 4$ Platypnoeaorthodeoxia (dyspnoea and arterial deoxygenation on standing) has been described, particularly in patients with patent foramen ovale. ${ }^{5}$ However, platypnoea was not our experience in the PAVM population, suggesting they may be able to compensate for acute falls in $\mathrm{CaO}_{2}$. The goal of the study was to quantify orthodeoxia and examine potential compensatory mechanisms to facilitate provision of appropriate information to PAVM patients.

The study was ethically approved by the Hammersmith, Queen Charlotte's, Chelsea, and Acton Hospital Research Ethics Committee (LREC 2000/5764). Full methods are presented in the online supplementary data supplement. In all, 258 consecutive patients with CT-proven PAVMs were prospectively and newly recruited (2005-2013) and evaluated as described. ${ }^{12}$ Pulse and oxygen saturation $\left(\mathrm{SaO}_{2}\right)$ were measured by pulse oximetry in supine and erect postures for $10 \mathrm{~min}$. Exercise capacity was stratified to a modified Medical Research Council (MRC) dyspnoea scale, with individuals classified as grade $1 \mathrm{a}$ if they participated in intense sporting activity at least three times per week. ${ }^{2}$

Full patient demographics are presented in online supplementary Table 1. Ages ranged from 16 to 90 (median 48) years. A total of $89(34.5 \%)$ were male. For 239
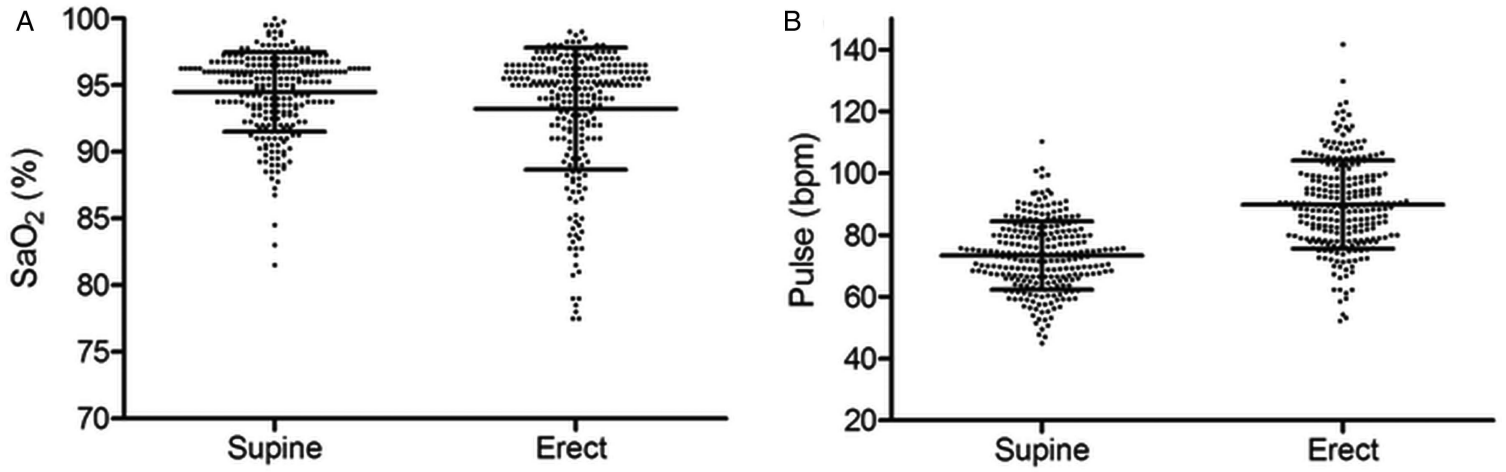

C

D
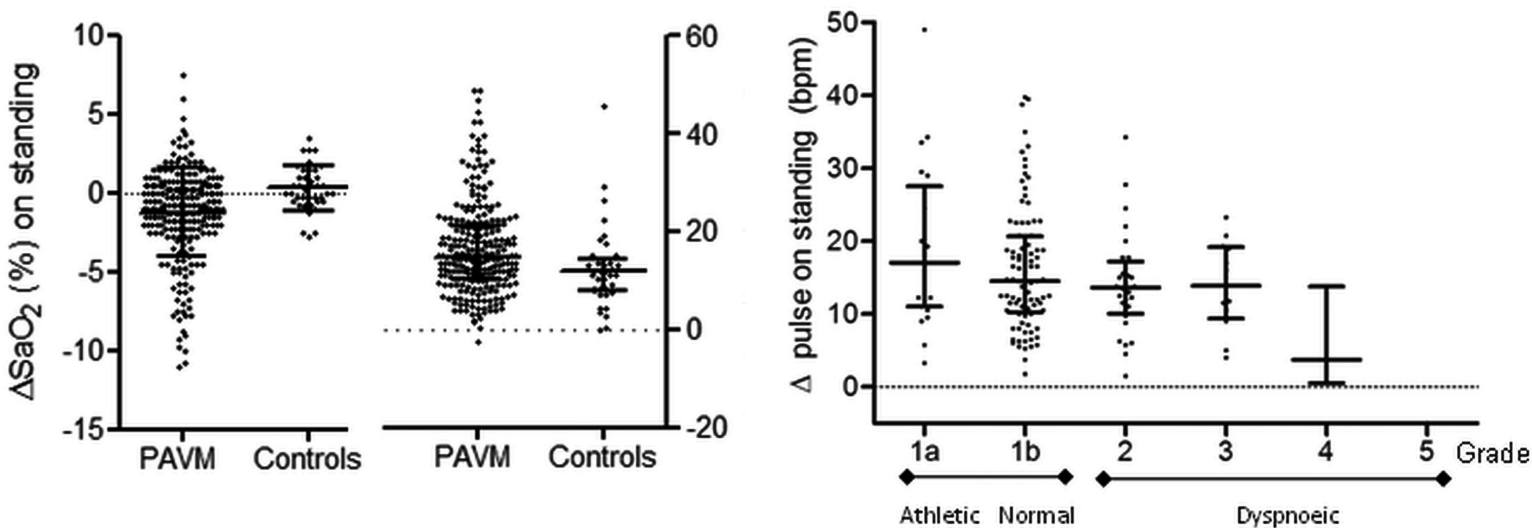

Figure 1 Postural changes in pulmonary arteriovenous malformation (PAVM) patients and controls. (A) Oxygen saturation $\left(\mathrm{SaO}_{2}\right)$ measured by pulse oximetry after 7-10 min lying supine, and 7-10 min standing in 257 PAVM patients. Values represent mean of recordings after 7, 8, 9 and 10 min in each posture. (B) Pulse after 7-10 min lying supine, and 7-10 min standing in 257 PAVM patients: bpm, beats per minute, ie, min ${ }^{-1}$. Values represent mean of recordings after 7, 8,9 and 10 min in each posture. (C) The change on standing in $\mathrm{SaO}_{2}$ (left axis and data) and pulse (right axis and data) in the 257 PAVM patients and 40 controls. These differences persisted once adjusted for age in multiple regression. The age-adjusted coefficients were for $\mathrm{SaO}_{2}-1.7(95 \% \mathrm{Cls}-2.6,-0.83) \%, \mathrm{p}<0.001$, and for pulse $5.5(95 \% \mathrm{Cls} 2.6,8.4) \mathrm{min}^{-1}, \mathrm{p}<0.001$. Further comparisons are provided in online supplementary Figures 2 and 3. (D) Difference in pulse rate between erect and supine postures in 165 PAVM patients, according to dyspnoea grade. Error bars represent median and IQR. 
(92.6\%), PAVMs were attributable to hereditary haemorrhagic telangiectasia (HHT). Overall, 50/221(22.6\%) were obese with a body mass index $>30$. Comorbidities were more common in patients with higher grade dyspnoea (see online supplementary Figure 1). Replicate $\mathrm{SaO}_{2}$ and pulse values demonstrated high within-patient reproducibility (see online supplementary Table 2).

Overall, erect $\mathrm{SaO}_{2}$ was significantly lower than supine $\mathrm{SaO}_{2}$ (figure $1 \mathrm{~A}$ ). In 75/ $257(29 \%)$ patients, the $\mathrm{SaO}_{2}$ fell by at least $2 \%$ on standing compared with the equivalent supine reading. A smaller fall of $1 \%-2 \%$ was present in a further $54 / 257$ (21\%) patients. None of these patients reported dyspnoea on standing (platypnoea), although one was unable to complete the $10 \mathrm{~min}$ standing due to dizziness. As expected, obese patients had lower supine $\mathrm{SaO}_{2}$ for their erect $\mathrm{SaO}_{2}$, and correspondingly less evidence of orthodeoxia (see online supplementary Figure 4).

Sudden falls in $\mathrm{SaO}_{2}$ reduce $\mathrm{CaO}_{2}$ per unit blood volume. However, there was a consistent increase in heart rate on standing (figure 1B). Orthostatic tachycardia was more pronounced in PAVM patients than 40 controls (figure $1 \mathrm{C}$, and online supplementary Figures 2 and 3), and in patients exhibiting greater falls in $\mathrm{SaO}_{2} / \mathrm{CaO}_{2}$ (see online supplementary Figure 5). Postural orthostatic tachycardia is normally viewed in a detrimental manner, but in this study, more marked orthostatic tachycardia was observed in patients with better exercise tolerance (figure 1D), whether analysed in five groups as shown, or in three groups of athletes (grade 1a), normal (grade 1b) and all dyspnoeic patients (grades 2-4).

To conclude, we provide an extensive consecutive series demonstrating that orthodeoxia is common in PAVM patients, though may be masked by obesity. Exuberant postural orthostatic tachycardia may be part of acute compensatory mechanisms that maintain tissue oxygen delivery when $\mathrm{CaO}_{2}$ falls suddenly on standing, and is associated with better exercise tolerance in PAVM patients.

V Santhirapala, ${ }^{1,2,3}$ B Chamali, ${ }^{1,3}$ H McKernan, ${ }^{4}$

H C Tighe, ${ }^{4}$ L C Williams, ${ }^{4}$ J T Springett, ${ }^{4} \mathrm{H}$ R Bellenberg, ${ }^{3}$ A J Whitaker, ${ }^{3}$ C L Shovlin ${ }^{1,4}$

${ }^{1} \mathrm{NHLI}$ Cardiovascular Sciences, Imperial College London, London, UK

${ }^{2}$ NHLI Respiratory Sciences, Imperial College London, London, UK

${ }^{3}$ Imperial College School of Medicine, Imperial College London, London, UK

${ }^{4}$ Respiratory Medicine, Hammersmith Hospital, Imperial College Healthcare NHS Trust, London, UK

Correspondence to Dr Claire L Shovlin, NHLI

Cardiovascular Sciences, Imperial Centre for Translational and Experimental Medicine, Imperial College London, Hammersmith Campus, Du Cane Road, London, W12 ONN, UK;

c.shovlin@imperial.ac.uk

Acknowledgements Funding was received from the National Institute of Health Research NIHR: London (NW) Comprehensive Local Research Network; patient donations; and Imperial College BSc project funds (to CLS for VS and BC).

Contributors VS generated the 2005-2010 database and analysed data. BC generated the 2010-2013 database. HM, HCT, LCW and JS performed pulmonary function measurements. HRB and AJW generated the control and HHT databases. CLS reviewed all patients, contributed to database generation, performed all statistical analyses, generated the figures/tables and wrote the article. All authors reviewed and approved the final article.

\section{Competing interests None.}

Ethics approval Hammersmith, Queen Charlotte's, Chelsea, and Acton Hospital Research Ethics Committee (LREC 2000/5764).

Provenance and peer review Not commissioned; externally peer reviewed.

Data sharing statement We fully concur with the principles of data sharing and will provide anonymised primary data in Excel format on request.
- Additional material is published online only. To view please visit the journal online (http://dx.doi.org/10.

1136/thoraxjnl-2014-205289).

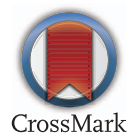

To cite Santhirapala V, Chamali B, McKernan H, et al. Thorax 2014;69:1046-1047.

Received 17 February 2014

Revised 4 March 2014

Accepted 14 March 2014

Published Online First 8 April 2014

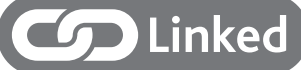

http://dx.doi.org/10.1136/thoraxjnl-2013-205028

Thorax 2014;69:1046-1047.

doi:10.1136/thoraxjnl-2014-205289

\section{REFERENCES}

1 Shovlin CL, Chamali B, Santhirapala V, et al. Ischaemic strokes in patients with pulmonary arteriovenous malformations and hereditary haemorrhagic telangiectasia: associations with iron deficiency and platelets. PLOS ONE 2014;9(2) e88812.

2 Santhirapala V, Williams LC, Tighe HC, et al. Arterial oxygen content is precisely maintained by graded erythrocytotic responses in settings of high/normal serum iron levels, and predicts exercise capacity. An observational study of hypoxaemic patients with pulmonary arteriovenous malformations. PLOS ONE 2014;9(3):e90777.

3 Ueki T, Hughes JMB, Peters AM, et al. Oxygen and 99mTc-MAA shunt estimations in patients with pulmonary arteriovenous malformations: effects of changes in posture and lung volume. Thorax 1994;49:327-31.

4 Thompson RD, Jackson J, Peters AM, et al. Sensitivity and specificity of radioisotope right-left shunt measurements and pulse oximetry for the early detection of pulmonary arteriovenous malformations. Chest 1999;115:109-13

5 Rodrigues P, Palma P, Sousa-Pereira L. Platypnea-orthodeoxia syndrome in review: defining a new disease? Cardiology 2012;123: $15-23$. 